\title{
Successful Treatment of Right-Sided Heart Thrombus with Pulmonary Embolism with Thrombolytic Therapy
}

Ehab Sobhy*, Tarek Alamaldine and Hilal Al Sabti

Sultan Qaboos University Hospital, Oman

\begin{abstract}
We report a case of a large mobile right-sided heart thrombus $(2.8 \mathrm{~cm} \times 2.7 \mathrm{~cm})$ complicated with pulmonary embolism. We planned to give thrombolytic therapy with an alteplase infusion and to repeat the TTE, and if the thrombus remained, to go ahead with surgical embolectomy with exploration of the right chambers and removal of the thrombus. Surgical removal of the thrombus with pulmonary embolectomy has been validated, but as it is a high-risk intervention, we were advised to try treatment with thrombolytic therapy first. Thrombolytic therapy resulted in complete disappearance of the thrombus, as documented by TTE. The patient was discharged home on oral anticoagulation with regular follow-up in outpatient clinic and lifelong anticoagulation was advised, as she was diagnosed to have type III protein S deficiency.
\end{abstract}

Keywords: Right heart thrombus pulmonary embolism; Thrombolytic protein s deficiency

\section{Case Report}

A female patient, 30 years old, was referred from a local health centre with history of sudden onset of shortness of breathing with mild chest pain. The patient had a history of abortion three weeks ago and she was treated with oral anti-hypertensive as she was diagnosed to have pregnancy-induced hypertension. On admission to the emergency department, she had tachypnea, tachycardia and cyanosis with oxygen saturation of $84 \%$ in room air. The vital signs were: pulse 110/min, Respiratory Rate (RR) 38/min, Blood Pressure (BP) 112/82 $\mathrm{mmHg}$. Heart sounds were normal with good breath sounds bilaterally. Arterial blood gas showed mild hypoxemia $\left(\mathrm{pO}_{2} 59.9 \mathrm{mmHg}\right)$ and ECG showed sinus tachycardia with a rate of $110 / \mathrm{min}$. Oxygen therapy was initiated with an oxygen mask and her saturation improved. Laboratory testing showed high D-dimer $34.3 \mathrm{ng} / \mathrm{ml}$ and a high lecuocytic count of 28.6 with neutrophils 23.8, troponin $0.18 \mathrm{ng} / \mathrm{ml}$, CRP 15 .

A chest angiography Computed Tomography (CT) showed extensive Pulmonary Embolism (PE) involving the right pulmonary artery and also showed a $2.9 \mathrm{~cm} \times 2.2 \mathrm{~cm}$ mass in the right atrium with no enhancement; this mass extended into the right ventricle. Low molecular weight heparin (enoxparine) was started at a dose of $80 \mathrm{mg}$ twice daily and the patient remained haemodynamically stable with good saturation with a $5 \mathrm{~L}$ oxygen mask.

Transthoracic Echocardiography (TTE) was done and showed a large mass measuring $2.8 \times 2.7 \mathrm{~cm}$ in the right atrium with a lobulated appearance and with a pedicle that seemed to be attached to the atrial septum. The mass was very mobile and was seen prolapsing in and out of the tricuspid valve, with moderate tricuspid valve regurgitaion with a peak gradient of $37 \mathrm{mmHg}$. Its appearance was highly suggestive of a right atrial myxoma (Figures 1 and 2). An ultrasound Doppler (of the veins of the lower limbs) was done and showed no evidence of DVT bilaterally.

The case was referred to cardiothoracic surgery for urgent surgical intervention, as there was no clear-cut evidence as to whether this mass was a myxoma or a thrombus.

Thrombolytic therapy was advised in an attempt at thrombolysis of the mass in the right atrium if it was a thrombus, and if it was a myxoma, to help in the reduction of the pulmonay artery pressure by thrombolysis of thrombi in the pulmonary artery, which would help us if we went for surgical excision of the right atrial mass.

Fibrinolytic therapy with tissue-type plasminogen activator (alteplase infusion: $100 \mathrm{mg}$ over 2 hours) was initiated. During the infusion of the drug, the patient became tachypnic with desaturation, which improved with oxygen supplementation with non-invasive ventilation. Enoxaparin $80 \mathrm{mg}$ twice daily was continued and warfarin was started orally.

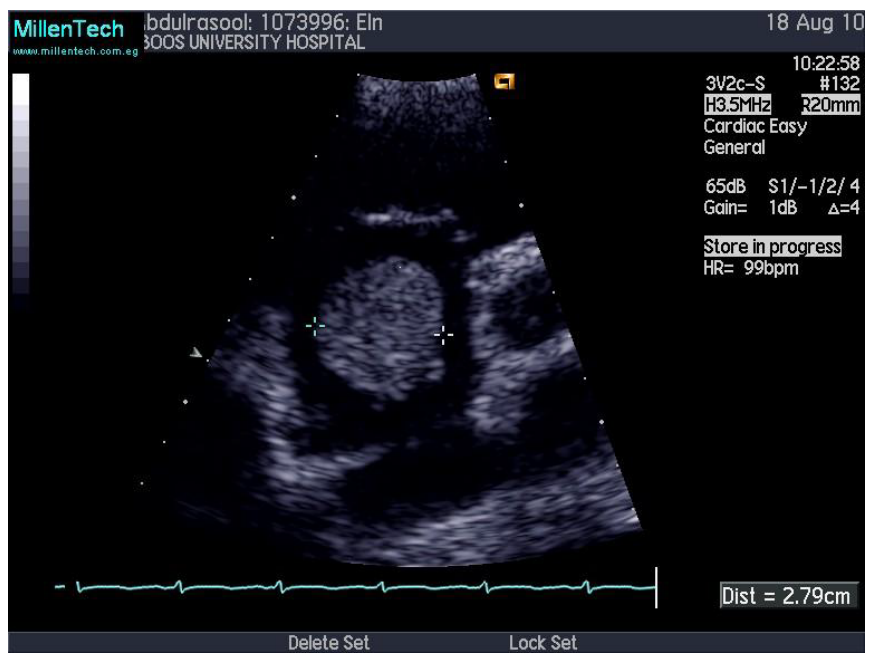

Figure 1: Appearance of a right atrial myxoma

*Corresponding author: Dr. Ehab Sobhy, Sultan Qaboos University Hospital, Oman, E-mail: mohehab2002@yahoo.com

Received August 06, 2013; Accepted August 26, 2013; Published September 02,2013

Citation: Sobhy E, Alamaldine T, Sabti HA (2013) Successful Treatment of RightSided Heart Thrombus with Pulmonary Embolism with Thrombolytic Therapy. J Cardiovasc Dis Diagn 1: 121. doi:10.4172/2329-9517.1000121

Copyright: ( 2013 Sobhy E, et al. This is an open-access article distributed under the terms of the Creative Commons Attribution License, which permits unrestricted use, distribution, and reproduction in any medium, provided the original author and source are credited. 
TTE was repeated about eight hours after the start of thrombolysis and showed complete disappearance of the right atrial mass (Figure 3).

CT chest angiography was repeated, and compared to the previous CT done before thromolytic therapy, there is evidence of complete resolution of the large atrioventricular filling defect that was seen previously, and apparently it had embolized to the left lower lobe pulmonary arteries, which was not seen previously.

The patient was fully investigated for the possible aetiology of this large right-sided heart thrombus formation. Blood investigations showed that the patient had type III Protein S deficiency, as the thrombophilia workup revealed low functional Protein S $(=0.249 \mathrm{iu} /$ $\mathrm{ml}$, Normal $=0.52-1.18)$ and low free Protein $\mathrm{S}$ antigenic $(=0.347 \mathrm{iu} / \mathrm{ml}$, $\mathrm{N}=0.62-1.3$ )

The patient was discharged home on oral anticoagulation with regular follow-up in the outpatient clinic and lifelong anticoagulation was advised, as she was diagnosed to have type III Protein S deficiency.

\section{Discussion}

Cardiac thrombus may be a complication of primary cardiac,

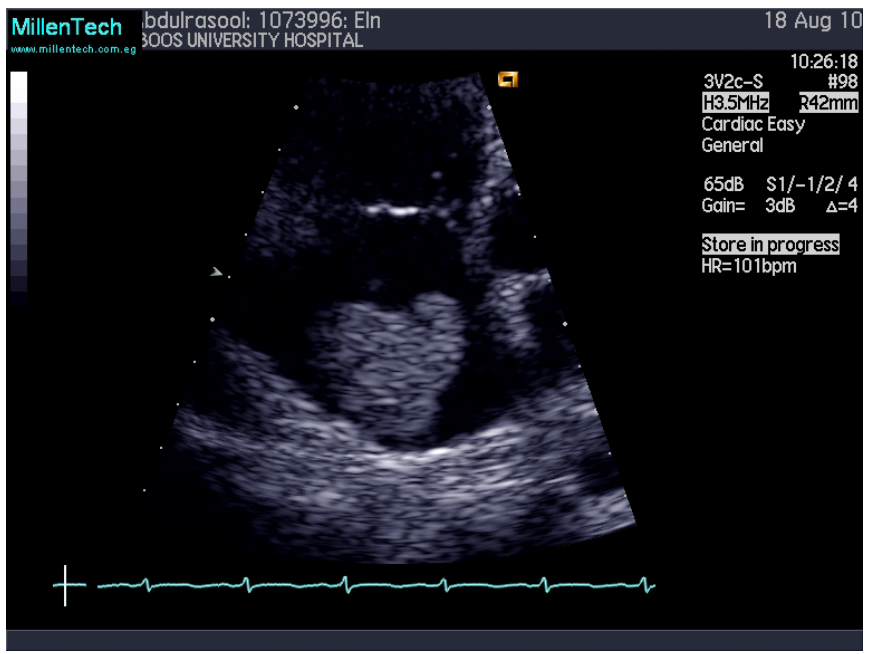

Figure 2: Appearance of a right atrial myxoma

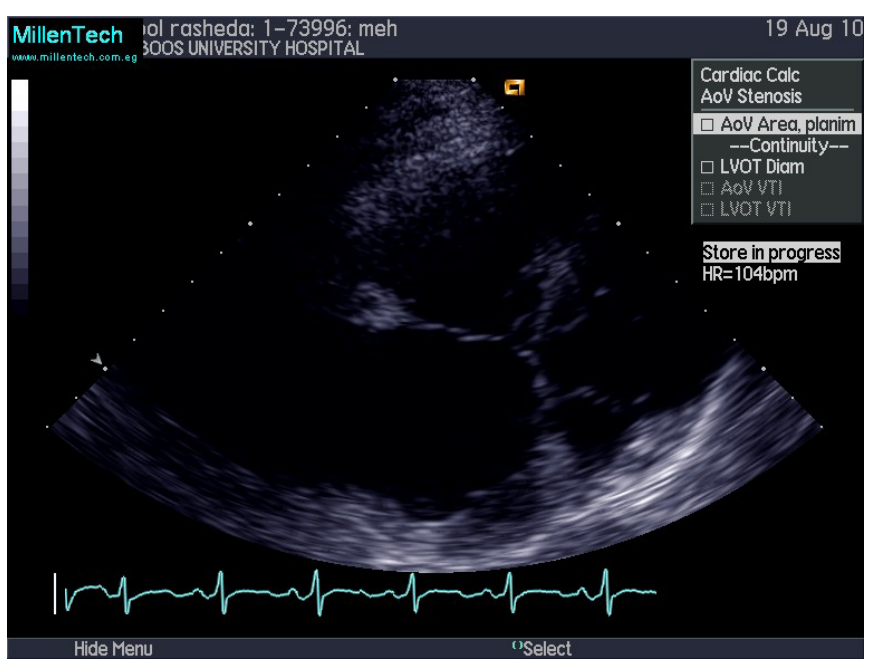

Figure 3: Complete disappearance of the right atrial mass. haematological and rheumatological disease [1]. Free-floating Right Heart Thrombi (FRHT) is a rare phenomenon, generally diagnosed when echocardiography is performed in patients with suspected or proven pulmonary embolism, and have a dismal prognosis [2]. Rightsided heart thrombi can be found in $4-18 \%$ of patients presenting with acute pulmonary embolism [3]. They may develop within the right heart chambers or originate from peripheral venous clots that become stuck in right heart structures on their way to the lungs [4]. The presence of a right heart thrombus in $\mathrm{PE}$ is relevant for the prognosis, as it predicts a higher mortality rate $(>44 \%)$ [5].

Sometimes, the differential diagnosis of an FRHT may be difficult. Other diagnoses - for instance, congenital structures such as a Chiari network, persistent eustachian or thebesian valves, or atrial septal aneurysms, or acquired conditions such as intracardiac tumors or devices and vegetations - need to be considered [6].

The literature on the treatment and therapeutic management of mobile right heart thrombus with pulmonary embolism gives no clear consensus. Treatment should be individualized according to the extent of the intracardiac thrombus (number and sizes of clots and their mobility and morphology), the likelihood of pre-existing pulmonary embolism, the patient's cardiopulmonary reserve, co-morbid conditions and local expertise with treatment modalities [7].

Several treatment options are available, including anticoagulation, embolectomy and thrombolysis. The success and survival rates of each approach vary, depending on the patient's clinical status [8].

Anticoagulation with heparin is generally considered to be the safest treatment, but its use has historically been associated with many complications, including potentially life- threatening ones, such as thrombocytopenia [9].

Surgical embolectomy with exploration of the right chambers and the pulmonary arteries under full cardiopulmonary bypass is the classic treatment. It has two drawbacks: It is not readily available in all medical centres, and it is sometimes associated with an extremely high mortality rate [10]

Because of the limitations of anticoagulation and embolectomy for right atrial thrombosis, thrombolysis is considered by some to be the treatment of choice. Preterm infants and newborn children with right atrial and intracardiac thrombosis have been successfully treated with thrombolytic therapy, without any complications $[11,12]$.

Thrombolytics have also been used safely in patients with right atrial thrombosis related to central venous catheters [13]. Even in patients with heparin-induced thrombocytopenia, thrombolysis can be used to destroy the clot in the right atrium [9].

Thrombolytic drugs have been approved by the Food and Drug Administration in cases of severe pulmonary embolism. Thrombolytic drugs include urokinase, streptokinase and Recombinant-Tissue Plasminogenic Activator (r-tPA). It seems reasonable to choose $\mathrm{r}$-tPA, which allows faster hemodynamic improvement, and also because its fibrinospecificity and its short half-life do not contraindicate surgical embolectomy when hemodynamic status continues to worsen [14].

Thrombolytic therapy is not without risk, however: It may cause the right atrial thrombus or its fragments to become dislodged and then to move into the pulmonary arteries [15].

Several cases of pulmonary embolism--possibly linked to thrombus fragmentation--have been reported, but there were no fatalities in 
patients who were haemodynamically stable at the onset of treatment [16].

Protein S deficiency is a rare condition and may be hereditary (autosomal dominant trait) or acquired; the latter is usually due to hepatic diseases or a vitamin $\mathrm{K}$ deficiency. Protein $\mathrm{S}$ is a vitamin $\mathrm{K}$-dependent anticoagulant protein. It functions as a cofactor of activated protein $\mathrm{C}$ to inactivate activated factor $\mathrm{V}(\mathrm{FVa})$ and activated factor VIII (FVIIIa). If there is a deficiency of Protein S, these clotting proteins remain activated, increasing the tendency for blood to clot, and this manifests clinically as Venous Thromboembolism (VTE). Recurrent thrombosis or a life-threatening thromboembolic event in a patient with PS deficiency is usually managed with long-term oral anticoagulation $[17,18]$.

Pregnancy is considered to be an acquired hypercoagulable state due to increased levels of coagulation factors, decreased levels of anticoagulants and decreased fibrinolytic activity. The gradual increase in hypercoagulability during normal pregnancy predisposes to Venous Thromboembolism (VTE), and to gestational vascular complications, including recurrent pregnancy loss and intrauterine growth restriction [19].

Proteins $\mathrm{C}$ and $\mathrm{S}$ are natural anticoagulants. Women of reproductive age who are deficient in protein $\mathrm{C}$, protein $\mathrm{S}$ or ATIII have a three times higher risk of thromboembolic disease than do men of the same age. A higher risk of spontaneous abortion in women with these deficiencies has been reported [20].

\section{Conclusion}

The most appropriate therapeutic approach for managing right heart thrombi remains to be determined, but our data suggest that thrombolytic therapy with $\mathrm{r}$-tPA is effective and readily available, and represents an alternative to surgery, especially if right heart thrombi are associated with pulmonary embolism. We also recommend that all cases with intracardiac thrombi should be investigated for thrombophilia.

\section{References}

1. Gurgun C, Sagcan A, Cinar CS, Yagdi T, Zoghi M, et al. (2000) Right atrial and ventricular thrombi in Behcet's disease: a case report and review of literature. Blood Coagul Fibrinolysis 11: 107-110.

2. Chapoutot L, Nazeyrollas P, Metz D, Maes D, Maillier B, et al. (1996) Floating right heart thrombi and pulmonary embolism: diagnosis, outcome and therapeutic management. Cardiology 87: 169-174.

3. Torbicki A, Galie N, Covezzoli A, Rossi E, De Rosa M, et al. (2003) Right heart thrombi in pulmonary embolism: results from the International Cooperative Pulmonary Embolism Registry. J Am Coll Cardiol 41: 2245-2251.
4. Casazza F, Bongarzoni A, Centonze F, Morpurgo M (1997) Prevalence and prognostic significance of right-sided cardiac mobile thrombi in acute massive pulmonary embolism. Am J Cardiol 79: 1433-1435.

5. de Vrey EA, Bax JJ, Poldermans D, Wall EE, Holman ER (2007) Mobile right heart thrombus and massive pulmonary embolism. Eur J Echocardiogr 8: 229 231.

6. Panidis IP, Kotler MN, Mintz GS, Ross J (1984) Clinical and echocardiographic features of right atrial masses. Am Heart J 107: 745-758.

7. Thompson CA, Skelton TN (1999) Thromboembolism in the right side of the heart. South Med J 92: 826-830.

8. Shah CP, Thakur RK, Ip JH, Xie B, Guiraudon GM, et al. (1996) Management of mobile right atrial thrombi: a therapeutic dilemma. J Card Surg 11: 428-431.

9. Janssens U, Breithardt OA, Greinacher A (1999) Successful thrombolysis of right atrial and ventricle thrombi encircling a temporary pacemaker lead in a patient with heparin- induced thrombocytopenia type II. Pacing Clin Electrophysiol 22: 678681.

10. Chartier L, Béra J, Delomez M, Asseman P, Beregi JP, et al. (1999) Freefloating thrombi in the right heart: diagnosis, management, and prognostic indexes in 38 consecutive patients. Circulation 99: 2779-2783.

11. Aspesberro F, Beghetti M, Oberhänsli I, Ozsahin H, Humbert J, et al. (1999) Local low-dose urokinase treatment of acquired intracardiac thrombi in preterm infants. Eur J Pediatr 158: 698-701.

12. Dufour C, Molinari AC, Tasso L, De Caro E, Rimini A, et al. (1997) Lysis of a right atrial thrombus of more than a week's duration by high dose urokinase in a one-year-old child. Haematologica 82: 357-359.

13. Nani R, Novello P, Decastello M, Cavarzerani A, Sarpellon M, et al. (1997) Right atrial thrombosis with concomitant thrombus attached to a central venous catheter.Clinical case. Minerva Anestesiol 63: 209-212.

14. Yeh KH, Hung KC, Lin FC, Yeh SJ, Wu D (2000) Successful lysis of righ and left heart thrombus by tissue plasminogen activator. Cathet Cardiovasc Intervent 49: 91-96.

15. Lepper W, Janssens U, Klues HG, Hanrath P (1996) Successful lysis of mobile right heart and pulmonary artery thrombi: diagnosis and monitoring by transesophageal echocardiography [letter]. Eur Heart J 17: 1603-1604.

16. Cracowski JL, Tremel F, Baguet JP, Mallion JM (1999) Thrombolysis of mobile right atrial thrombi following severe pulmonary embolism. Clin Cardiol 22: 151 154

17. Castoldi E, Hackeng TM (2008) Regulation of coagulation by protein S. Curr Opin Hematol 15: 529-536.

18. Adachi $T$ (2005) Protein $S$ and congenital protein $S$ deficiency: the most frequent congenital thrombophilia in Japanese. Curr Drug Targets 6: 585-592.

19. Sarig G, Vidergor G, Brenner B (2009) Assessment and management of highrisk pregnancies in women with thrombophilia. Blood Rev 23: 143-147.

20. Blumenfeld Z, Brenner B (1999) Thrombophilia-assoctiated pregnancy wastage. Fertil Steril 72: 765-774. 